\title{
Field evaluation of multistrain biofertilizer for improving the productivity of different
} mungbean genotypes

\author{
Zahir Ahmad Zahir, , , Maqshoof Ahmad ${ }^{2}$, Thomas H. Hilger ${ }^{3}$, Abubakar Dar ${ }^{1}$, Shahid Riaz Malik ${ }^{4}$, \\ Ghulam Abbas ${ }^{5}$ and Frank Rasche ${ }^{3}$ \\ ${ }^{1}$ Institute of Soil and Environmental Sciences, University of Agriculture Faisalabad-Pakistan \\ ${ }^{2}$ Department of Soil Science, University College of Agriculture and Environmental Sciences, the Islamia University of \\ Bahawalpur, Pakistan \\ ${ }^{3}$ Institute of Agricultural Sciences in the Tropics (Hans-Ruthenberg-Institute), University of Hohenheim (490), \\ 70599-Stuttgart, Germany \\ ${ }^{4}$ Pulses Program, National Agricultural Research Center, Islamabad, Pakistan \\ ${ }^{5}$ Nuclear Institute for Agriculture \& Biology (NIAB), Faisalabad
}

\begin{abstract}
Mungbean can successfully be grown in the small slots present in the existing cropping systems that may increase the farmer income and can also restore soil fertility. The inoculation of crop plants with bacterial inoculants has the potential to increase crop productivity even under different soil and climatic conditions. A field experiment was conducted to evaluate the effectiveness of multi-strain biofertilizer prepared through combined use of Rhizobium phaseoli and Pseudomonas fluorescens and Bacillus subtilis for enhancing the growth, nodulation and productivity of ten mungbean genotypes under field conditions, and effect of inoculation on total bacterial DNA (population) in soil. The experiment was laid out in randomized complete block design (RCBD) with factorial arrangements and three replications. Results revealed that inoculation with multistrain biofertilizer increased the nodule numbers, growth, and yield under different mungbean genotypes when compared with their respective uninoculated control. The genotypes showed different productive potentials either with or without inoculation under field conditions. The genotype NCM 2015 yielded more but inoculation was more effective with genotypes NM 17, NM 19 and NCM-25210 under field conditions of Bahawalpur. Results of $16 \mathrm{~S} r R N A$ analysis showed a higher number of gene copies in the rhizosphere of inoculated plants of all mungbean genotypes than those of uninoculated plants. Maximum total bacterial population was observed in the rhizosphere of inoculated plants in NM 11 that was significantly better than un-inoculated control plants of the same mungbean line but non-significant when compared with other lines under inoculation. It is concluded that the use of multistrain biofertilizer prepared through combined use of Rhizobium and PGPR strains containing ACC-deaminase could be an effective approach to improve growth, nodulation and yield of mungbean genotypes. The response of different genotypes to the inoculation varied significantly. So, research for the development of inoculum for different advanced genotypes should be continued and more emphasis should be deployed to develop biofertilizers with efficient strains to use them under different climate and soil conditions.
\end{abstract}

Keywords: mungbean, intensification, profitability, sustainability, biofertilizers

\section{Introduction}

The small landholder farmers in Pakistan grow only major crops such as cotton, rice, wheat and sugarcane and they have negligible place for minor crops including pulses in the cropping systems. This may be due to lack of interest and awareness regarding new technologies and supporting crops. The incorporation of legume crops in the cropping system may increase the profitability and can also restore soil fertility. Mung bean is one of the important pulse crops grown in the world. It is a cheap source of high quality nutrition including $24.2 \%$ protein, $1.3 \%$ fat, $60.4 \%$ carbohydrate, $4 \%$ minerals and 3\% vitamins (Afzal et al., 2008). Apart from its dietary role, it is also important from soil fertility point of view due to its ability to form symbiotic relation with Rhizobium that have the ability of fixing atmospheric nitrogen (Achakzai et al., 2012). It is a warm season crop that can easily fit into the existing cropping systems without disturbing them. Diversification of local production systems through inclusion of mungbean can be profitable for farmers and can improve soil fertility. Nitrogen is one of the most limiting plant nutrients that decrease crop productivity. Despite of its availability in air (more than 79\%), it is not available to plants directly. However, it can only be utilized and fixed by soil microbes including Rhizobium making it available not only to plants but also for entire ecosystem (Ahmad et al., 2013a).

In addition to Rhizobium, soil inhabiting plant growth promoting rhizobacteria (PGPR) are also associated with

\footnotetext{
*Email: zazahir@yahoo.com
} 
mung bean and play a significant role in plant growth and development. These bacteria play a vital role in plant growth and their presence ensures normal functioning of several rhizospheric and plant metabolic processes (Nadeem et al., 2014). These PGPR colonize the rhizosphere and promote plant growth by various direct or indirect mechanisms including nitrogen fixation, metabolites production (plant growth regulators etc.), nutrient solubilization, mineralization of organic matter, pathogen control as well as play a significant role in induction of stress tolerance in plants (Ahmad et al., 2013b; Nadeem et al., 2014).

However, under intensive field conditions, the activity of Rhizobium and PGPR is poor, that not only affect mung bean production but also soil health (Ashraf et al., 2003). Several reports indicated that the combined Rhizobium and PGPR significantly enhance the plant growth and rhizospheric activity, resulting in significant improvement in yield and productivity of legume crops (Anjum et al., 2006; Qureshi et al., 2013; Ahmad et al., 2013a; 2014). Therefore, present study was conducted to evaluate the effectiveness of multistrain biofertilizer prepared through combined use of Rhizobium, Pseudomonas fluorescens and and effect of inoculation on total bacterial DNA (population) in soil.

\section{Inoculum preparation}

The bacterial cultures were prepared in $250 \mathrm{~mL}$ Erlenmeyer flasks. For this purpose, after preparation of culture media, the flasks were inoculated respective bacterial strains. The liquid cultures were incubated for 72 hours at $30{ }^{\circ} \mathrm{C}$ with continuous shaking at $100 \mathrm{rpm}$ in shaking incubator (Model SI9R-2, Shellab-USA). After incubation for three days, the bacterial cells were harvested by centrifugation at $9000 \mathrm{rpm}$ and $22{ }^{\circ} \mathrm{C}$ for 20 minutes (Model: UNIVERSAL 320R, Hettich Germany). The supernatant was discarded and the pellets were re-suspended in sterilized distilled water. This washing procedure was repeated and the pellets were dissolved in sterilized distilled water to get uniform cell density $\left(\mathrm{OD}=0.45\right.$; cell count $10^{8} \mathrm{cfu} \mathrm{mL}^{-1}$ ).

\section{Seed inoculation and field experiment}

For seed inoculation, pre-pelleted and re-suspended broth cultures of PGPR strains i.e. Mk20 (Pseudomonas fluorescens) and Y16 (Bacillus subtilis) and Rhizobium

Table 1: Physico-chemical characteristics of the soil

\begin{tabular}{lll}
\hline Parameter & Unit & Value \\
\hline $\mathrm{EC}_{\mathrm{e}}$ & $\mathrm{dS} \mathrm{m}^{-1}$ & 2.1 \\
$\mathrm{pH}$ & -- & 7.9 \\
Organic matter & $\%$ & 0.47 \\
Total Nitrogen & $\%$ & 0.062 \\
Available Phosphorus & $\mathrm{mg} \mathrm{kg}^{-1}$ & 3.0 \\
Extractable Potassium & $\mathrm{mg} \mathrm{kg}^{-1}$ & 77 \\
Saturation percentage & $\%$ & 34 \\
Textural class & --- & Sandy loam \\
\hline
\end{tabular}

Bacillus Subtilis (PGPR) for enhancing the growth, nodulation efficiency and productivity of different mung bean genotypes under field conditions.

\section{Materials and Methods}

\section{Field experiment}

A field experiment was conducted at research area of the Department of Soil Science, Islamia University of Bahawalpur by using 10 genotypes/accessions. These genotypes were taken from the gene pool maintained at Crop Sciences Research Institute, NARC, IslamabadPakistan. The objective of the experiment was to evaluate the effectiveness of multi-strain biofertilizer prepared through combined use of Rhizobium phaseoli and Pseudomonas fluorescens and Bacillus subtilis for enhancing the growth, nodulation efficiency and productivity of different genotypes under field conditions i.e. M9 (Rhizobium phaseoli) with uniform cell density were mixed in equal proportion and vortexed for 5 minutes to ensure homogenized cell density of different bacterial strains for preparation of slurry. The slurry was prepared with broth culture, sterilized peat, and sugar solution $(10 \%)$ in 4:5:1 ratio as a carrier. In the case of un-inoculated control, seeds were coated with the sterilized (autoclaved) peat treated with sterilized broth.

The sowing was done on April 04, 2016 and harvested on July 16, 2016. The experiment was laid out in Randomized Complete Block Design (RCBD) with factorial arrangements and three replications. Before sowing, a composite soil sample was collected from experimental site and analyzed for physicochemical properties (Table 1) by following the protocols as described by Ryan et al. (2001). 
Recommended dose of N, P, K fertilizers (20: 60: 60 $\mathrm{kg} \mathrm{ha}^{-1}$ ) were applied as urea, diammonium phosphate and sulphate of potash, respectively. All fertilizers were applied as basal dose at the time of sowing. The crop was irrigated with canal water and all agronomic practices were performed as per requirement of the crop. The data regarding nodulation were recorded at flowering while growth and yield parameters were taken at harvest upon maturity.

\section{Analysis of bacterial community variation}

For the analysis of total bacterial DNA, five best performing mungbean lines were selected. Rhizosphere soil samples were collected after 50 days of sowing. Five plants were uprooted, and non-adhering soil was removed by shaking. The soil adhering to plant roots was collected by scrapping for use as rhizospheric soil. Composite sample was prepared by thorough mixing of soil collected from five plants. Soil samples were collected $(50 \mathrm{~g})$ and placed individually into plastic bags, transported to the laboratory and freeze-dried. The samples were transported to the Institute of Agricultural Sciences, University of Hohenheim, Germany, and freeze-dried until further analysis.

Total genomic DNA for bacteria was extracted using a commercially available DNA extraction kit (FastDNA® Spin for Soil Kit, MP Biomedicals, Solon, Ohio, USA). Extracted DNA was quantified photometrically using Nanodrop (Nanodrop ND-1000, Nanodrop Technologies, Wilmington, DE, USA) and purified DNA was stored at $-20^{\circ} \mathrm{C}$.

For qPCR analysis of $16 \mathrm{~S}$ rRNA gene, $25 \mu \mathrm{L}$ PCR cocktails were prepared containing $9.0 \mu \mathrm{L}$ aqua dest, 12.5 $\mu \mathrm{L} 1 \mathrm{X}$ SYBR green master mix (Applied Biosystems, Foster City, CA, USA), $0.50 \mu \mathrm{L}$ of T4 gene 32 protein $(500 \mu \mathrm{g} \mathrm{mL}-1$, MP Biomedicals), $0.4 \mu \mathrm{M}$ of each oligonucleotide and $5 \mathrm{ng}$ of template DNA. The PCR reactions were run on StepOnePlus ${ }^{\mathrm{TM}}$ Real-Time PCR System (Applied Biosystems).

Reaction was started with initial denaturation at $95^{\circ} \mathrm{C}$ temperature for 10 minutes, followed by 40 cycles of denaturation at $95^{\circ} \mathrm{C}$ for $30 \mathrm{~s}$, annealing at $55^{\circ} \mathrm{C}$ for $35 \mathrm{~s}$ and elongation at $72^{\circ} \mathrm{C}$ for $45 \mathrm{~s}$. Melting curve analysis of amplicons was conducted to confirm that fluorescence signals originated from specific amplicons and not from primer dimers or other artifacts. The DNA samples were processed in triplicate reactions, while standard curves were generated using duplicate 10 -fold dilutions of isolated plasmid DNA (Rasche et al., 2011; Musyoki et al., 2016). Automated analysis of PCR amplicon quality and quantity was performed with StepOne ${ }^{\mathrm{TM}}$ software version 2.2 (Applied Biosystems).

\section{Statistical analysis}

The data were analyzed using Analysis of Variance techniques in Statistix $8.1^{\circledR}$ software and means were compared using LSD at 5\% level of probability to see the difference among treatment means (Montgomery, 2013).
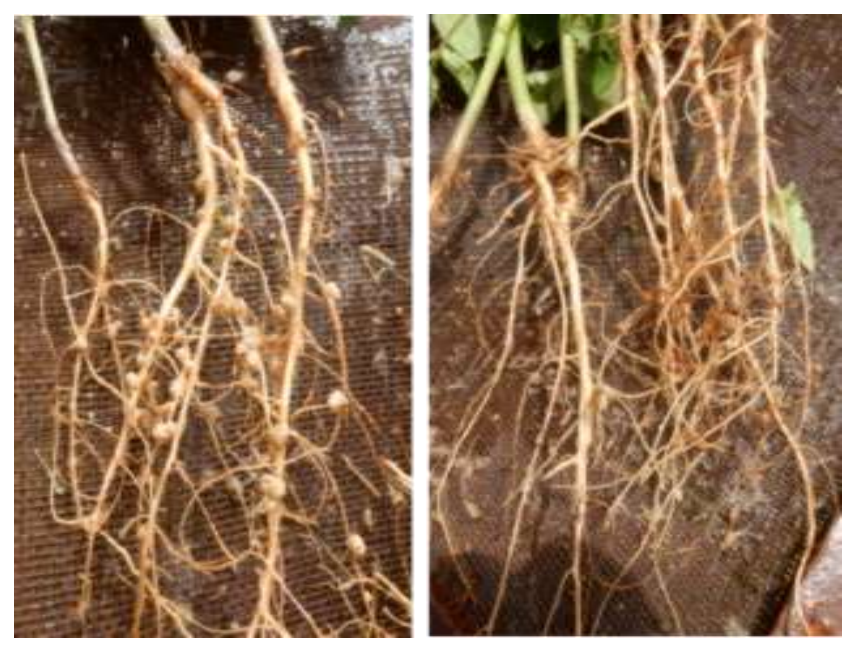

Picture 1: Comparison in number and size of nodules in inoculated (left) and un-inoculated (right) plants of genotype NCM 2013

\section{Results}

Results showed that inoculation was effective in improving the nodulation (Picture 1). Genotypes also showed variable response to inoculation, but this variation was nonsignificant in most of the cases (Table 2). Maximum nodules (17.1) were observed in inoculated plants of NCM 2013 followed by NM 11 of inoculated treatment with 16.2 nodules plant ${ }^{-1}$. Minimum nodules were observed in uninoculated treatment of NM 16. Under inoculated treatment, minimum nodules were observed in plants of NCM 2015 that were non-significantly less than all other genotypes except NM 11 and NCM 2013. Results regarding the effect of inoculation on nodules fresh and dry weight of different mungbean genotypes (Table 2) showed that maximum nodule fresh weight $\left(2.1 \mathrm{~g} \mathrm{plant}^{-1}\right)$ due to inoculation was observed in NM 17 while maximum nodule dry weight $\left(0.108 \mathrm{~g} \mathrm{plant}^{-1}\right)$ was recorded in the inoculated plants of NCM 2015. A significant effect of inoculation on nodule fresh and dry weight was observed in most of the varieties as compared to their respective un-inoculated controls.

The results (Table 3) depicted that different mungbean genotypes showed variation in their plant height both with and without inoculation. Under un-inoculated conditions, 
Table 2: Effect of inoculation with multistrain biofertilizer on nodulation in different mungbean genotypes (average of 3 replicates)

\begin{tabular}{|c|c|c|c|c|c|c|}
\hline \multirow[b]{2}{*}{ Genotype } & \multicolumn{2}{|c|}{ Number of nodules plant ${ }^{-1}$} & \multicolumn{2}{|c|}{ Nodules fresh weight $\left(\mathrm{g} \mathrm{plant}^{-1}\right)$} & \multicolumn{2}{|c|}{ Nodules dry weight $\left(\mathrm{g} \mathrm{plant}^{-1}\right)$} \\
\hline & Un-inoculated & Inoculated & Un-inoculated & Inoculated & Un-inoculated & Inoculated \\
\hline NM 11 & $8.3 \mathrm{c}-\mathrm{f}$ & $16.2 \mathrm{ab}$ & $0.44 \mathrm{~d}-\mathrm{g}$ & $1.73 \mathrm{a}-\mathrm{c}$ & $0.042 \mathrm{de}$ & $0.090 \mathrm{ab}$ \\
\hline AZRI 06 & $9.7 b-f$ & 12.8 a-d & $0.57 \mathrm{~d}-\mathrm{g}$ & $1.16 \mathrm{a}-\mathrm{f}$ & $0.062 \mathrm{~cd}$ & $0.085 \mathrm{a}-\mathrm{c}$ \\
\hline NM 16 & $3.3 \mathrm{f}$ & 10.6 a-e & $0.49 \mathrm{~d}-\mathrm{g}$ & $1.93 \mathrm{ab}$ & $0.048 \mathrm{de}$ & $0.101 \mathrm{ab}$ \\
\hline NM 17 & $12.7 \mathrm{a}-\mathrm{d}$ & $11.3 \mathrm{a}-\mathrm{e}$ & $0.30 \mathrm{eg}$ & $2.01 \mathrm{a}$ & $0.032 \mathrm{ef}$ & $0.099 \mathrm{ab}$ \\
\hline NCM 2015 & $9.3 b-f$ & $8.8 \mathrm{c}-\mathrm{f}$ & $0.65 \mathrm{~d}-\mathrm{g}$ & $1.87 \mathrm{ab}$ & $0.077 \mathrm{bc}$ & $0.108 \mathrm{a}$ \\
\hline NM 19 & $7.0 \mathrm{~d}-\mathrm{f}$ & $13.8 \mathrm{a}-\mathrm{d}$ & $0.17 \mathrm{~g}$ & $1.31 \mathrm{a}-\mathrm{d}$ & $0.016 \mathrm{f}$ & $0.090 \mathrm{ab}$ \\
\hline NM 18 & $9.0 \mathrm{c}-\mathrm{f}$ & $14.5 \mathrm{a}-\mathrm{c}$ & $0.50 \mathrm{~d}-\mathrm{g}$ & $1.79 \mathrm{a}-\mathrm{c}$ & $0.083 \mathrm{bc}$ & $0.089 \mathrm{ab}$ \\
\hline NM 06 & $7.1 \mathrm{~d}-\mathrm{f}$ & $14.7 \mathrm{a}-\mathrm{c}$ & $0.24 \mathrm{fg}$ & $1.19 \mathrm{a}-\mathrm{e}$ & $0.016 \mathrm{f}$ & $0.079 \mathrm{bc}$ \\
\hline NCM-252-10 & $6.9 \mathrm{~d}-\mathrm{f}$ & $13.0 \mathrm{a}-\mathrm{d}$ & $0.86 \mathrm{c}-\mathrm{g}$ & $1.03 \mathrm{~b}-\mathrm{g}$ & $0.079 \mathrm{bc}$ & $0.083 \mathrm{bc}$ \\
\hline NCM 2013 & 4.7 ef & $17.1 \mathrm{a}$ & $0.56 \mathrm{~d}-\mathrm{g}$ & $1.66 \mathrm{a}-\mathrm{c}$ & $0.065 \mathrm{~cd}$ & $0.089 \mathrm{ab}$ \\
\hline $\operatorname{LSD}(p \leq 0.05)$ & \multicolumn{2}{|c|}{7.0355} & \multicolumn{2}{|c|}{0.9433} & \multicolumn{2}{|c|}{0.239} \\
\hline
\end{tabular}

Means sharing the same letter(s) do not differ significantly at $p \leq 0.05$.

Table 3: Effect of inoculation with multistrain biofertilizer on plant height $(\mathrm{cm})$, and shoot fresh and dry weights $\left(\mathrm{g} \mathrm{plant}^{-1}\right)$ in different mungbean genotypes (average of 3 replicates)

\begin{tabular}{lcccccc}
\hline \multirow{2}{*}{ Genotype } & \multicolumn{2}{c}{ Plant height $(\mathbf{c m})$} & \multicolumn{2}{c}{ Shoot dry weight $\left(\mathbf{g ~ p l a n t}^{-1}\right)$} & \multicolumn{2}{c}{ Root dry weight $\left(\mathbf{g ~ p l a n t ~}^{-\mathbf{1}}\right)$} \\
\cline { 2 - 7 } & Un-inoculated & Inoculated & Un-inoculated & Inoculated & Un-inoculated & Inoculated \\
\hline NM 11 & $47.40 \mathrm{a}-\mathrm{f}$ & $49.84 \mathrm{a}-\mathrm{d}$ & $9.65 \mathrm{a}-\mathrm{c}$ & $10.02 \mathrm{ab}$ & $0.60 \mathrm{e}$ & $0.99 \mathrm{a}$ \\
AZRI 06 & $46.07 \mathrm{a}-\mathrm{f}$ & $46.87 \mathrm{a}-\mathrm{f}$ & $6.48 \mathrm{~d}-\mathrm{f}$ & $8.29 \mathrm{~b}-\mathrm{d}$ & $0.38 \mathrm{f}$ & $0.87 \mathrm{ab}$ \\
NM 16 & $39.97 \mathrm{ef}$ & $47.29 \mathrm{a}-\mathrm{f}$ & $6.46 \mathrm{~d}-\mathrm{f}$ & $6.53 \mathrm{~d}-\mathrm{f}$ & $0.61 \mathrm{de}$ & $0.84 \mathrm{a}-\mathrm{c}$ \\
NM 17 & $43.64 \mathrm{~b}-\mathrm{f}$ & $44.07 \mathrm{a}-\mathrm{f}$ & $5.33 \mathrm{f}$ & $5.67 \mathrm{ef}$ & $0.38 \mathrm{f}$ & $0.82 \mathrm{a}-\mathrm{d}$ \\
NCM 2015 & $46.50 \mathrm{a}-\mathrm{f}$ & $47.93 \mathrm{a}-\mathrm{f}$ & $11.57 \mathrm{a}$ & $11.91 \mathrm{a}$ & $0.93 \mathrm{ab}$ & $1.02 \mathrm{a}$ \\
NM 19 & $39.20 \mathrm{f}$ & $41.99 \mathrm{~d}-\mathrm{f}$ & $5.37 \mathrm{f}$ & $6.76 \mathrm{~d}-\mathrm{f}$ & $0.65 \mathrm{c}-\mathrm{e}$ & $0.73 \mathrm{~b}-\mathrm{e}$ \\
NM 18 & $45.31 \mathrm{a}-\mathrm{f}$ & $53.25 \mathrm{a}$ & $8.45 \mathrm{~b}-\mathrm{d}$ & $8.74 \mathrm{~b}-\mathrm{d}$ & $0.73 \mathrm{~b}-\mathrm{e}$ & $0.92 \mathrm{ab}$ \\
NM 06 & $43.07 \mathrm{c}-\mathrm{f}$ & $48.95 \mathrm{a}-\mathrm{e}$ & $7.65 \mathrm{~b}-\mathrm{f}$ & $7.28 \mathrm{c}-\mathrm{f}$ & $0.86 \mathrm{ab}$ & $0.86 \mathrm{ab}$ \\
NCM-252-10 & $39.10 \mathrm{f}$ & $52.59 \mathrm{ab}$ & $8.05 \mathrm{~b}-\mathrm{e}$ & $8.48 \mathrm{~b}-\mathrm{d}$ & $0.96 \mathrm{a}$ & $0.92 \mathrm{ab}$ \\
NCM 2013 & $41.91 \mathrm{~d}-\mathrm{f}$ & $51.75 \mathrm{a}-\mathrm{c}$ & $7.81 \mathrm{~b}-\mathrm{e}$ & $8.04 \mathrm{~b}-\mathrm{e}$ & $0.87 \mathrm{ab}$ & $1.00 \mathrm{a}$ \\
LSD (p $\leq$ & \multicolumn{2}{c}{2.3958} & & & 0.2083 \\
$0.05)$ & \multicolumn{2}{c}{9.3191} & &
\end{tabular}

Means sharing the same letter(s) do not differ significantly at $p \leq 0.05$.

the maximum plant height was observed by the genotype NM 11 that was non-significant with all other genotypes under un-inoculated conditions. The inoculation gave significant improvement in plant height of NCM-252-10 and NCM 2013 with respect to their un-inoculated controls. While maximum plant height $(53.25 \mathrm{~cm})$ was observed in NM 18 which was non-significant as compared to uninoculated treatment of NM18. All other genotypes gave non-significant improvement in plant height due to inoculation.

Data regarding the effect of multi-strain biofertilizer on shoot dry weight (Table 3) showed that shoot biomass was improved due to inoculation in all the mungbean genotypes, maximum shoot dry weight was observed in NCM 2015 in inoculated plants that was $11.91 \mathrm{~g} \mathrm{plant}^{-1}$. However, 
maximum improvement in shoot dry weight was observed in AZRI 06 that was $28 \%$ higher than uninoculated control was non-significant with un-inoculated control plants. Maximum improvement in grain yield due to inoculation

Table 4: Effect of inoculation with multistrain biofertilizer on 1000 -grain weight $(\mathrm{g})$ and grain yield $\left(\mathrm{t} \mathrm{ha}^{-1}\right) \mathrm{of}^{-}$ different mungbean genotypes (average of 3 replicates)

\begin{tabular}{|c|c|c|c|c|}
\hline \multirow[b]{2}{*}{ Genotype } & \multicolumn{2}{|c|}{ 1000-grain weight $(\mathrm{g})$} & \multicolumn{2}{|c|}{ Grain yield $\left(\mathrm{t} \mathrm{ha}{ }^{-1}\right)$} \\
\hline & Un-inoculated & Inoculated & Un-inoculated & Inoculated \\
\hline NM 11 & $61.00 \mathrm{a}-\mathrm{c}$ & $67.23 \mathrm{a}-\mathrm{c}$ & $1.20 \mathrm{c}$ & $1.28 \mathrm{bc}$ \\
\hline AZRI 06 & $59.11 \mathrm{bc}$ & $60.58 \mathrm{a}-\mathrm{c}$ & $0.98 \mathrm{~d}$ & $1.03 \mathrm{~d}$ \\
\hline NM 16 & $62.70 \mathrm{a}-\mathrm{c}$ & $56.65 \mathrm{c}$ & $1.17 \mathrm{c}$ & $1.23 \mathrm{c}$ \\
\hline NM 17 & $61.50 \mathrm{a}-\mathrm{c}$ & $64.06 \mathrm{a}-\mathrm{c}$ & $0.84 \mathrm{ef}$ & $1.03 \mathrm{~d}$ \\
\hline NCM 2015 & $63.45 \mathrm{a}-\mathrm{c}$ & $72.92 \mathrm{a}$ & $1.35 \mathrm{ab}$ & $1.39 \mathrm{a}$ \\
\hline NM 19 & $62.09 \mathrm{a}-\mathrm{c}$ & $71.02 \mathrm{ab}$ & $0.80 \mathrm{f}$ & $0.94 \mathrm{de}$ \\
\hline NM 18 & $56.31 \mathrm{c}$ & $60.33 \mathrm{a}-\mathrm{c}$ & $0.75 \mathrm{fg}$ & $0.84 \mathrm{ef}$ \\
\hline NM 06 & $63.34 \mathrm{a}-\mathrm{c}$ & $57.48 \mathrm{c}$ & $0.68 \mathrm{~g}$ & $0.77 \mathrm{fg}$ \\
\hline NCM-252-10 & $54.71 \mathrm{c}$ & $56.36 \mathrm{c}$ & $0.81 \mathrm{f}$ & $0.97 \mathrm{~d}$ \\
\hline NCM 2013 & $55.06 \mathrm{c}$ & $62.07 \mathrm{a}-\mathrm{c}$ & $0.95 \mathrm{de}$ & $1.05 \mathrm{~d}$ \\
\hline $\operatorname{LSD}(p \leq 0.05)$ & \multicolumn{2}{|c|}{12.784} & \multicolumn{2}{|c|}{0.1090} \\
\hline
\end{tabular}

Means sharing the same letter(s) do not differ significantly at $p \leq 0.05$.

Table 5: Effect of inoculation with multistrain biofertilizer on total bacterial DNA analyzed through 16S qPCR in the rhizosphere of different mungbean genotypes (average of 3 replicates)

\begin{tabular}{lcc}
\hline \multirow{2}{*}{ Variety } & \multicolumn{2}{c}{ Total bacterial DNA (million copies $\mathbf{g}^{-1}$ dry soil) } \\
\cline { 2 - 3 } & Un-inoculated & Inoculated \\
\hline NM 11 & $1379.6 \quad$ bc & $3481.8 \mathrm{a}$ \\
NM 16 & 1643.3 a-c & $2015.0 \mathrm{a}-\mathrm{c}$ \\
NM 17 & $577.7 \quad \mathrm{c}$ & $2441.6 \mathrm{a}-\mathrm{c}$ \\
NCM 2015 & $608.9 \mathrm{bc}$ & $2596.9 \mathrm{ab}$ \\
NCM 2013 & 800.4 bc & $2022.1 \mathrm{a}-\mathrm{c}$ \\
\hline
\end{tabular}

Means sharing the same letter(s) do not differ significantly at $p \leq 0.05$; Standard Error for Comparison $=950.13$; Critical Value for Comparison $=1996.1$

plants. The improvement in shoot dry weight due to inoculation was non-significant in all the genotypes. A significant improvement in root dry weight was observed due to use of multi-strain biofertilizer in most of the mungbean genotypes. Maximum improvement in root dry weight was observed in AZRI 06 followed by NM 17, NM 11 and NM 16 where significant difference in root dry weight of inoculated and uninoculated plants was observed.

Results (Table 4) depicted that inoculation improved the 1000-grain weight and grain yield of mungbean but this improvement was non-significant in most of the cases. Maximum 1000-grain weight and grain yield was observed by the genotype NCM 2015 in the inoculated treatment that was observed by the genotype NM 17 where $23 \%$ increase in grain yield over the un-inoculated control plants was observed. Inoculation gave significant improvement in grain yield of the genotypes NM 17, NM 19 and NCM-25210 as compared to un-inoculated control. All other genotypes showed non-significant improvement. However, the improvement in 1000-grain weight due to inoculation was non-significant in all the genotypes.

The results (Table 5) showed that inoculation with multi-strain biofertilizer has improved the indigenous bacterial population in the rhizosphere of different mungbean lines as observed by the abundance of $16 \mathrm{~S}$ rRNA gene (total bacteria). In general, a higher number of gene 
copies were determined in the rhizosphere of inoculated plants of all mungbean genotypes than those of uninoculated plants. Maximum number of copies of $16 \mathrm{~S}$ rRNA gene (total bacteria) was observed in the rhizosphere of inoculated plants in NM 11 that was significantly better than un-inoculated control plants of the same mungbean line but non-significant when compared with other lines under inoculation. The inoculation also showed improved total bacterial population (16S rRNA gene) in the rhizosphere of other mungbean lines but the improvement was statistically non-significant when compared with respective un-inoculated control plants. The varieties showed non-significant effect on the rhizosphere bacteria either with inoculation or without inoculation.

\section{Discussion}

Incorporation of mungbean into existing cropping systems of Pakistan can be helpful to increase the profitability of small landholders in the country. Under agro-ecological conditions of Pakistan, the nodulation in mungbean is poor due to poor performance of indigenous rhizobial strains in our soils. In mungbean, using productive varieties that can establish effective symbiosis with inoculated rhizobium and rhizobacterial strains is possibly the most cost-effective way to achieve improvement in its productivity. The use of biofertilizers containing efficient bacterial strains can be possible solution to increase the nodulation and ultimately the yield of mungbean crop (Ahmad et al., 2013a). Present study was conducted to evaluate the efficiency of multistrain biofertilizer for increasing the nodulation, growth and yield of different mungbean genotypes under field conditions in Bahawalpur. The effect of this fertilizer on rhizosphere bacterial population was also studied through $16 \mathrm{~S}$ rRNA analysis. The results showed that inoculation with multistrain biofertilizer containing efficient strains of Rhizobium and $P$. fluorescens and $B$. subtilis significantly improved the nodulation in mung bean genotypes. The increase in nodulation was however varied with different mungbean genotypes. The better performance of these strains in some mungbean genotypes might be due to better symbiotic association of these strains with specific genotypes. The bacterial strains respond differentially to different crop varieties and species under low nutrient soil conditions (Imran et al., 2015). They suggested paying equal attention for selecting plant genotype and bacterial strains to get better nodulation and yield of legume crop. Moreover, the improvement in nodulation due to inoculation might be due to stimulation of root growth of mungbean by PGPR which ultimately increased the surface area for rhizobial infection during the process of nodulation, so more nodules formed in inoculated plants (Ahmad et al., 2011, 2014). In another study, Sindhu and Dadarwal (2001) reported improvement in nodulation due to co-inoculation and they linked this increase in nodulation with release of hydrolytic enzymes i.e. cellulases by PGPR. These enzymes are responsible for the production of more infection sites on root hairs by rupturing the cell wall and making it more feasible for rhizobial infection (Hubbell et al., 1978).

More nodulation means the increased availability of nitrogen that results improvement in growth and yield of leguminous crops. In present study, the inoculation increased the root and shoots growth that resulted in enhanced yield of mung bean genotypes. On average, the inoculation in current study has a positive effect on grain yield as compared to earlier estimates (Ronner et al., 2016) however the benefit of inoculation was minimal in some specific cases as observed in some earlier studies (Heerwaarden et al., 2017). The increased growth and yield due to combined used of Rhizobium and Pseudomonas strains can be the result of better nutrient availability, presence of microbial metabolites such as indole acetic acid, siderophores, microbial enzymes and exopolysaccharides which were produced by inoculated strains (Ahmad et al., 2011, 2013b). The results of our study are consistent with the report by Kyei-Boahen et al. (2017) which showed that inoculation of cowpea increased nodulation, grain yield and grain $\mathrm{N}$ contents under field conditions. Similarly, the increased growth and yield due to better reproductive growth and fruit setting has also been reported in previous studies (Samavat et al., 2012; Ahmad et al., 2013a). It has been demonstrated in previous studies that low phosphorus availability in soils constrains nitrogen fixation and crop productivity. This might be due to important role $\mathrm{P}$ both nodulation, nitrogen fixation and plant growth processes through enhancement in root hair formation and root development (Nziguheba et al., 2016), along with nodule initiation as well as energy source for nitrogen fixation process that may directly affect the nitrogenase activity and photosynthesis (Hogh-Jensen et al., 2002; Kyei-Boahen et al., 2017). The increased growth and yield due to inoculation with $\mathrm{P}$ solubilizing bacterial strains might also be due to increased $\mathrm{P}$ uptake leading to higher reproductive growth and flower development. The more $\mathrm{P}$ uptake as a result of indigenous phosphate solubilization by colonized $P$. fluorescens might be one of the reasons for improved growth and yield of inoculated crops (Egamberdieva et al., 2010; Sanchez et al., 2014).

Inoculation with multi-strain biofertilizer has improved the indigenous bacterial population in the rhizosphere of different mungbean lines as observed by the abundance of $16 \mathrm{~S}$ rRNA gene (total bacteria) in present studies. The increased bacterial population due to inoculation was due to the better root colonization of inoculated strains (Ahmad $e t$ al., 2011). More colonization of bacterial strains due to 
inoculation resulted in better root proliferation that improved the quality of root exudates which ultimately provided more nutrition for bacteria growing in the rhizosphere.

Different mungbean genotypes responded differently to inoculation with multistrain biofertilizer. The better performance of biofertilizer in some mungbean genotypes might be due to better symbiotic association of bacterial strains with specific genotypes that is an evidence for support of the idea that crop, soil, and climate-specific biofertilizer should be developed for better performance of biofertilizers under specific agro-ecological conditions.

\section{Conclusions}

The use of multistrain biofertilizer prepared through combined use of Rhizobium and PGPR strains containing ACC-deaminase could be an effective approach to improve growth, nodulation and yield of mungbean genotypes. The response of different genotypes to the inoculation varied significantly. So, research for the development of inoculum for different advanced genotypes should be continued and more emphasis should be deployed to develop biofertilizers with efficient strains to use them under different climate and soil conditions.

\section{Acknowledgement}

The authors acknowledge the technical support of Zafar Iqbal, Carolin Rohl and and M.K. Musyoki for successful completion of these studies. We also acknowledge the support of Institute of Agricultural Sciences in the Tropics and Sub-tropics, University of Hohenheim. This work was financially supported by the Federal Ministry for Economic Cooperation and Development, Germany under the umbrella of the Beans with Benefits project run by the World Vegetable Center, Taiwan, with partners in Germany, Pakistan, and Uzbekistan.

\section{References}

Achakzai, A.K.K., M.O. Liasu and O.J. Popoola, 2012. Effect of mycorrhizal inoculation on the growth and phytoextraction of heavy metals by maize grown in oil contaminated soil. Pakistan Journal of Botany 44: 221230.

Afzal, M.A., A.N.M.M.M. Murshad, M.A. Bakar, A. Hamid and A.B.M. Slahuddin. 2008. Mung bean cultivation in Bangladesh. Pulse Resarch Station. Bangladesh Agriculture Research Institute, Ghazipur. Bangladesh.

Ahmad, M. Z.A. Zahir, S.M. Nadeem, F. Nazli, M. Jamil and M.U. Jamshaid. 2014. Physiological response of mungbean to Rhizobium and Pseudomonas based biofertilizers under salinity stress. Pakistan Journal of Agricultural Sciences 5: 1-8.

Ahmad, M., Z.A. Zahir, F. Nazli, F. Akram, M. Arshad and M. Khalid. 2013b. Effectiveness of halo-tolerant, auxin producing Pseudomonas and Rhizobium strains to improve osmotic stress tolerance in mung bean (Vigna radiata L.). Brazilian Journal of Microbiology 44:1341-1348.

Ahmad, M., Z.A. Zahir, H.N. Asghar and M. Asghar. 2011. Inducing salt tolerance in mung bean through coinoculation with Rhizobium and PGPR containing ACC-deaminase. Canadian Journal of Microbiology 57: 578-589.

Ahmad, M., Z.A. Zahir, M. Khalid, F. Nazli and M. Arshad. 2013a. Efficacy of Rhizobium and Pseudomonas strains to improve physiology, ionic balance and quality of mung bean under salt-affected conditions on farmer's fields. Plant Physiology and Biochemistry 63: 170-176.

Anjum, M.S., Z.I. Ahmid and C.A. Rauf. 2006. Effect of Rhizobium inoculation and nitrogen fertilizer on yield and yield component of mung bean. International Journal of Agriculture and Biology 8: 238-240.

Ashraf, M., M. Mueen-ud-din and N.H. Warraich. 2003. Production efficiency of mungbean (Vigna radiata $\mathrm{L}$.) as affected by seed inoculation and NPK application. International Journal of agriculture and biology 2:179. 180.

Egamberdieva, D., Z. Kucharova, K. Davranov, G. Berg, N. Makarova, T. Azarova, V. Chabotar, I. Tikhonovich, F. Kamilova, S. Validov and B. Lugtenberg. 2010. Bacteria able to control foot and root rot and promote growth of cucumber in salinated soils. Biology and Fertility of Soil 47:197-205.

Heerwaarden, J., F. Baijukya, S. Kyei-Boahen, S. AdjeiNsiah, P. Ebanyat, N. Kamai, E. Wolde-meskel, F. Kanampiu, B. Vanlauwe and K. Giller. Soyabean response to rhizobium inoculation across sub-Saharan Africa: Patterns of variation and the role of promiscuity. Agriculture, Ecosystems and Environment. DOI: 10.1016/j.agee.2017.08.016.

Hogh-Jensen, H., J.K. Schjoerring, and J.F. Soussana. 2002. The influence of phosphorus deficiency on growth and nitrogen fixation of white clover plants. Annals of Botany, 90: 745-753.

Hubbell, D.H., V.M. Morales and M. Umali-Garcia. 1978. Pectolytic enzymes in Rhizobium. Applied and Environmental Microbiology 35: 210-213.

Imran, A., M.S. Mirza, T.M. Shah, K. A. Malik, and F.Y. Hafeez. 2015. Differential response of kabuli and desi chickpea genotypes toward inoculation with PGPR in different soils. Frontiers in Microbiology, 6: 859. doi: 10.3389/fmicb.2015.00859. 
Kyei-Boahen, S., C.E.N. Savala, D. Chikoye and R. Abaidoo. 2017. Growth and yield responses of cowpea to inoculation and phosphorus fertilization in different environments. Frontier in Plant Sciences, https://doi.org/10.3389/fpls.2017.00646.

Montgomery, D.C., 2013. pp. 98-100. Design and analysis of experiments. 8th Ed. John Wiley and Sons Inc, Newyork USA.

Musyoki, M.K., G. Cadisch, J. Zimmermann, H. Wainwright, F. Beed, F. Rasche. Soil properties, seasonality and crop growth stage exert a stronger effect on rhizosphere prokaryotes than the fungal biocontrol agent Fusarium oxysporum f. sp. strigae. Applied Soil Ecology 105: 126-136.

Nadeem, S.M., M. Ahmad, Z.A. Zahir, A. Javaid and M. Ashraf. 2014. The role of mycorrhizae and plant growth promoting rhizobacteria (PGPR) in improving crop productivity under stressful environments. Biotechnology Advances 32: 429-448.

Nziguheba, G., S. Zingore, J. Kihara, R. Merckx, S. Njoroge, A. Otinga, et al. 2016. Phosphorus in smallholder farming systems of sub-Saharan Africa: implications for agricultural intensification. Nutrient Cycling in Agroecosystems, 104: 321-340.

Qureshi, M.A., M.A. Shakir, A. Iqbgal, N. Akhtar and A. Khan. 2011. Co-inoculation of phosphate solubilizing bacteria and rhizobia for improving growth and yield of mungbean (Vigna radiata L.). The Journal of Animal \& Plant Sciences 21: 491-497.

Rasche, F., D. Knapp, C. Kaiser, M. Koranda, B. Kitzler, S. Zechmeister-Boltenstern, A. Richter and A. Sessitsch. 2011. Seasonality and resource availability control bacterial and archaeal communities in soils of a temperate beech forest. ISME Journal 5: 389-402.
Ronner, E., A.C. Franke, B. Vanlauwe, M. Dianda, E. Edeh, B. Ukem, A. Bala, J. van Heerwaarden, K.E. Giller. 2016. Understanding variability in soybean yield and response to P-fertilizer and rhizobium inoculants on farmers' fields in northern Nigeria. Field Crops Research, 186: 133-145.

Ryan, J., G. Estefan and A. Rashid. 2001. Soil and Plant Analysis Laboratory Manual, 2nd Ed. International Center for Agriculture in Dry Areas (ICARDA), Syria.

Samavat, S., S. Samavat, S. Mafakheri and M.J. Shakouri. 2012. Promoting common bean growth and nitrogen fixation by the co-inoculation of Rhizobium and Pseudomonas fluorescens isolates. Bulgarian Journal of Agricultural Science 18: 387-395.

Sánchez, A.C., R.T Gutiérrez, R.C. Santana, A.R. Urrutia, M. Fauvart, J. Michiels and J. Vanderleyden. 2014. Effects of co-inoculation of native Rhizobium and Pseudomonas strains on growth parameters and yield of two contrasting Phaseolus vulgaris L. genotypes under Cuban soil conditions. European Journal of Soil Biology 62: 105-112.

Sindhu, S.S., and K.R. Dadarwal. 2001. Chitinolytic and cellulolytic Pseudomonas sp. antagonistic to fungal pathogens enhances nodulation by Mesorhizobium sp. Cicer in chickpea. Microbiological Research 156: 353358. 